\title{
Fabrication, characterization and evaluation of mesoporous activated carbons from agricultural waste: Jerusalem artichoke stalk as an example
}

\author{
Lei $\mathrm{YU}^{1,2,3}$, Chen $\mathrm{TU}^{2}$, Yongming LUO $(\bowtie)^{1,2}$ \\ 1 Key Laboratory of Soil Environment and Pollution Remediation, Institute of Soil Science, Chinese Academy of Sciences, Nanjing 210008, China \\ 2 Key Laboratory of Coastal Zone Environmental Processes, Institute of Coastal Zone Research, Chinese Academy of Sciences, Yantai 264003, China \\ 3 Department of Environmental Engineering, Nanjing Forestry University, Nanjing 210037, China
}

(C) Higher Education Press and Springer-Verlag Berlin Heidelberg 2014

\begin{abstract}
This work explores the feasibility of Jerusalem artichoke stem (JAS), an agricultural waste, as an alternative precursor for fabrication of mesoporous activated carbon (MAC) via conventional $\mathrm{ZnCl}_{2}$ activation. The as-prepared JAS-MACs were characterized by thermogravimetric, nitrogen gas adsorption isotherm and high resolution scanning electron microscopy analysis. The interacting effects of chemical dosage, activation temperature and time on the mesoporosity, mesopore volume and carbon yield were investigated, and further optimized by response surface methodology (RSM). The Brunauer-Emmett-Teller surface area, mesoporosity and mesopore volume of the JAS-MAC prepared under optimum condition were identified to be $1631 \mathrm{~m}^{2} \cdot \mathrm{g}^{-1}$, $90.16 \%$ and $1.11 \mathrm{~cm}^{3} \cdot \mathrm{g}^{-1}$, respectively. Compared with commercial activated carbons, this carbon exhibited a comparable monolayer adsorption capacity of $374.5 \mathrm{mg}$ $\cdot \mathrm{g}^{-1}$ for Methylene Blue dye. The findings suggest that RSM could be an effective approach for optimizing the pore structure of fabricated activated carbons.
\end{abstract}

Keywords mesoporous activated carbon, response surface methodology, adsorption isotherm, agricultural wastes

\section{Introduction}

Jerusalem artichoke, an important agricultural cash crop, distributes widely in tropical, temperate and frigid Zone [1]. It is estimated that the plant area of Jerusalem artichoke in China has exceeded 2.6 thousands square kilometer and the output reached 10.7 million tons in year 2010, and the

Received March 3, 2013; accepted July 11, 2013

E-mail: ymluo@yic.ac.cn production of Jerusalem artichoke is expected to keep on growing in the future. This arouses environmental problems for the treatment of Jerusalem artichoke stalks (JAS) wastes, which have a high content of lignin. Today, the produced JAS wastes are mostly incinerated, and only a small portion is used for fuel production or other uses [2]. While incineration of JAS results in atmosphere pollution, and fuels production faces difficulties in lignin conversion, preparing activated carbon from JAS might offer an attractive new avenue for the agricultural waste disposal and resource recycle.

Activated carbons, attributed to their large specific surface area and pore volume, have been widely used as adsorbents in a variety of industrial and environmental applications [3]. However, conventional activated carbons have large pore dimensions, usually in microporous range (diameter, $d<2 \mathrm{~nm}$ ) and a relatively small development of mesoporosity, thus they are not suitable for treatment of wastewaters containing large-molecule pollutants (e.g., reactive dyes, long-chain organic compounds and medicine compounds) $[4,5]$. To facilitate the entry of large molecules into the pore structure, carbon materials with a high proportion of mesopores are needed because the mesopores (diameter, $2<d<50 \mathrm{~nm}$ ) are the main transport arteries for the adsorbates [6].

The preparation of activated carbon with highly mesoporosity is influenced by three main factors: chemical dosage $\left(X_{1}\right)$, activation temperature $\left(X_{2}\right)$ and activation time $\left(X_{3}\right)$. Thus a preliminary study on the effect of these factors on the carbon characteristics was carried out in order to determine the most important ones and their regions of interest [7-9]. According to the Box-Behnken design (BBD) table, 15 activated carbons were prepared by varying the values of $X_{1}, X_{2}$, and $X_{3}$ in suitable ranges and further optimized by Response surface methodology 
(RSM). This method has been widely used for the optimization of various processes in food chemistry, material science and biotechnology [10], but is scarcely reported for the optimization the pore structures, i.e. mesoporosity, of activated carbon during fabrication $[11,12]$.

The aims of this study were to explore the feasibility of fabricating mesoporous activated carbon (MAC) from JAS, and to optimize the fabrication process by using RSM. The mesoporosity $\left(Y_{1}\right)$, mesopore volume $\left(Y_{2}\right)$ and total carbon $\left(Y_{3}\right)$ of activated carbons were three optimization targets. The prepared activated carbons were characterized by scanning electron microscopy (SEM), thermogravimetric analysis (TGA) and $\mathrm{N}_{2}$ gas adsorption/desorption isotherm. The mesopore characteristic of resulting carbons prepared under optimum condition was validated by methylene blue (MB) adsorption tests. The isotherms, kinetics and thermodynamics of adsorption were investigated to evaluate the adsorption characteristics of the prepared adsorbent.

\section{Methods}

\subsection{Activated carbon preparation}

JAS were obtained from an experimental field near Yantai City, Shandong Province, China. They were washed thoroughly with distilled water to remove dust particles and then dried at $105^{\circ} \mathrm{C}$. The dried samples were mechanically crushed and sieved, so that JAS powder with a particle size $<200 \mu \mathrm{m}$ was obtained to enable more efficient chemical activation. The JAS particles and $\mathrm{ZnCl}_{2}$ were then mixed with water to form a slurry, and was kept at $85^{\circ} \mathrm{C}$ for $6 \mathrm{~h}$ to ensure complete reaction. The chemical dosages (mass ratios of $\mathrm{ZnCl}_{2}$ to JAS) were set at 1, 2.5 and 4 (as shown in Table 1). After $\mathrm{ZnCl}_{2}$ chemical impregnation, the mixed samples were dried at $105^{\circ} \mathrm{C}$ and used for pyrolysis. Pyrolysis of the chemical-activated JAS samples was performed in a tube type resistance furnace under high-purity nitrogen gas with a flow rate of $50 \mathrm{~mL} \cdot \mathrm{min}^{-1}$. The pyrolysis temperature and activation time are shown in the experimental design table (Table 1). After the gas activation step, the carbons were washed with $3 \mathrm{~mol} \cdot \mathrm{L}^{-1}$ $\mathrm{HCl}$ and hot water to remove the $\mathrm{ZnCl}_{2}$ and inorganic residues three times. The resulting carbons were finally dried at $105^{\circ} \mathrm{C}$ and stored for characterization.

\subsection{Characterization}

The specific surface area and pore structure characteristics of the resulting carbons were determined by nitrogen adsorption at $77.15 \mathrm{~K}$ using an automatic Micromeritics TriStar II 3020 pore size and surface area analyzer. The Brunauer-Emmett-Teller (BET) surface area was calculated from the isotherm using the Brunauer-Emmett-Teller (BET) Equation [4]. The single point total volume $\left(V_{\text {Total }}\right)$ was assessed by the amount of adsorbed nitrogen expressed in liquid form at a relative pressure of approximately $0.98 \mathrm{~atm}$. The micropore volume $\left(V_{\text {micro }}\right)$ and mesopore surface area $\left(S_{\text {meso }}\right)$ were analyzed according to the $t$-plot method5. The pore size distribution was calculated using the Barrett-Joyner-Halenda (BJH) method $[4,6]$. The morphologies of raw materials and prepared

Table 1 Box-Behnken design matrix and experimental results

\begin{tabular}{|c|c|c|c|c|c|c|c|c|c|}
\hline \multirow{2}{*}{ run } & \multicolumn{6}{|c|}{ independent variables } & \multicolumn{3}{|c|}{ responses } \\
\hline & $x_{1}$ & $x_{2}$ & $x_{3}$ & $X_{1}$ & $X_{2}$ & $X_{3}$ & $Y_{1}$ & $Y_{2}$ & $Y_{3}$ \\
\hline$\overline{1}$ & 1 & 0 & 1 & 4.0 & 600 & 3 & 93.1 & 1.359 & 33.0 \\
\hline 2 & 1 & 1 & 0 & 4.0 & 800 & 2 & 89.2 & 1.151 & 35.0 \\
\hline 3 & 0 & 0 & 0 & 2.5 & 600 & 2 & 90.4 & 0.933 & 35.5 \\
\hline 4 & 0 & 1 & 1 & 2.5 & 800 & 3 & 76.7 & 0.629 & 31.0 \\
\hline 5 & -1 & 0 & -1 & 1.0 & 600 & 1 & 14.2 & 0.121 & 38.5 \\
\hline 6 & 0 & 0 & 0 & 2.5 & 600 & 2 & 89.9 & 0.952 & 34.0 \\
\hline 7 & -1 & 1 & 0 & 1.0 & 800 & 2 & 11.4 & 0.074 & 35.5 \\
\hline 8 & -1 & -1 & 0 & 1.0 & 400 & 2 & 23.3 & 0.200 & 44.0 \\
\hline 9 & 0 & -1 & -1 & 2.5 & 400 & 1 & 59.5 & 0.452 & 43.5 \\
\hline 10 & 0 & 1 & -1 & 2.5 & 800 & 1 & 82.7 & 0.811 & 32.0 \\
\hline 11 & 0 & 0 & 0 & 2.5 & 600 & 2 & 89.6 & 0.941 & 36.0 \\
\hline 12 & 1 & 0 & -1 & 4.0 & 600 & 1 & 94.7 & 1.544 & 34.0 \\
\hline 13 & -1 & 0 & 1 & 1.0 & 600 & 3 & 18.6 & 0.129 & 36.5 \\
\hline 14 & 0 & -1 & 1 & 2.5 & 400 & 3 & 70.3 & 0.640 & 38.5 \\
\hline 15 & 1 & -1 & 0 & 4.0 & 400 & 2 & 77.2 & 0.672 & 34.5 \\
\hline
\end{tabular}


carbons were analyzed by high resolution Field emission SEM (FE-SEM, Hitachi S-4800, Japan). TGA were carried out on a Mettler TGA/DSC1 thermogravimetric analyzer. The samples were analyzed at a temperature range of $25^{\circ} \mathrm{C}-800^{\circ} \mathrm{C}$ with an increasing velocity of $10^{\circ} \mathrm{C} \cdot \mathrm{min}^{-1}$ under nitrogen gas flow.

\subsection{Experimental design and data analysis}

A three factor-tree coded level BBD was used to obtain optimum conditions for the critical factors [13]. The actual values of the independent variables $\left(X_{i}\right)$ were coded to $x_{i}$ according to following equation:

$$
x_{i}=\frac{X_{i}-\bar{x}_{i}}{\Delta x_{j}} \quad i=1,2,3, \ldots, k,
$$

where $x_{i}$ is the dimensionless value of the independent variable, $X_{i}$ represents the real value of the independent variable, $\bar{x}_{i}$ is the real value of the independent variable at the center point, and $\Delta x_{j}$ is the step change. The chemical dosage $\left(X_{1}\right)$, pyrolysis temperature $\left(X_{2}\right)$ and activation time $\left(X_{3}\right)$ were chosen as three independent variables in the MAC preparation process. Mesoporosity, $V_{\text {meso }}$ and carbonaceous yield were selected as the dependent variables to evaluate the characteristics of the resulting activated carbons. The response variables were fitted to the general model of Eq. (2) to investigate the relationship between the dependent variable and the independent variables using the regression method:

$$
Y=\beta_{o}+\sum_{i=1}^{j} \beta_{i} X_{i}+\sum_{i=1}^{k} \beta_{i i} X_{i}^{2}+\sum_{i}^{i<j} \sum_{j} \beta_{i j} X_{i} X_{j},
$$

where, $Y$ is the response variable to be modeled, $X_{i}$ and $X_{j}$ are independent variables which may influence $Y$, and $\beta_{i S}$ are model coefficients calculated from the experimental data. Design Expert software (version 8.0, Stat-Ease, Inc., Minneapolis, MN, USA) was used for regression and graphical analysis of the data. Finally, two additional experiments were conducted to verify the validity of the statistical experimental strategies.

\subsection{MB adsorption experiments}

Batch experiments were carried out in a set of $50 \mathrm{~mL}$ Erlenmeyer flasks, in which $25 \mathrm{~mL}$ of MB solutions with initial concentrations ranging from 50 to $400 \mathrm{mg} \cdot \mathrm{L}^{-1}$ and $0.01 \mathrm{~g}$ of carbons were added. These flasks were shaken at $120 \mathrm{r} \cdot \mathrm{min}^{-1}$ at determined temperature for $4 \mathrm{~h}$ to reach equilibrium of solid-solution mixture. The concentrations of MB in the solutions were determined using a ultraviolet and visible spectrophotometer (TU-1810, Purkinje Co. LTD, China) at $664 \mathrm{~nm}$ wavelength, and the amount of MB adsorbed by carbonaceous materials at equilibrium $\left(q_{\mathrm{e}}\right.$, $\mathrm{mg} \cdot \mathrm{g}^{-1}$ ) was calculated as follows:

$$
q_{\mathrm{e}}=\frac{\left(C_{0}-C_{\mathrm{e}}\right) V}{m},
$$

where $V$ is the volume of solution (L), $m$ is the adsorbent dosage $(\mathrm{g}), C_{0}$ and $C_{\mathrm{e}}$ are initial and equilibrium dye concentrations $\left(\mathrm{mg} \cdot \mathrm{L}^{-1}\right)$, respectively.

\section{Results and discussion}

\subsection{Characterization of resulting carbons}

For facilitate the comparison, samples were named MAC_a_b_c, where a, b, and c represents $\mathrm{ZnCl}_{2}$ dosage, activated temperature $\left({ }^{\circ} \mathrm{C}\right)$ and time $(\mathrm{h})$, respectively. TGA of resulting carbons are presented in the Supporting Information Fig. S1 (in supplementary information). A small mass loss of JAS is observed at temperatures below $200^{\circ} \mathrm{C}$, which can be attributed to loss of water (Fig. S1(a)). The thermal degradation of JAS began at $220^{\circ} \mathrm{C}$ and was stabilized near $500^{\circ} \mathrm{C}$. As shown in Fig. S1 (b), the differential thermal analysis displays a wide band with a shoulder at approximately $280^{\circ} \mathrm{C}$ and a maximum point at $350^{\circ} \mathrm{C}$, which may be associated with hemicellulose, cellulose and lignin decomposition [14]. Whereas, the weight loss of the three resulting carbons were quite small $(<15 \%)$, and no burn-off appeared at higher temperatures $\left(>600^{\circ} \mathrm{C}\right)$, indicating that the raw JAS had been completely carbonized.

The morphologies of JAS and the resulting carbons are presented in Fig. S2. The diameter of raw JAS particle was in the range of 40 to $50 \mu \mathrm{m}$, and stoma with an average diameter of $5 \mu \mathrm{m}$ was distributed on the coarse surface (Figs. S2(a) and S2(b)). As shown in Figs. S2(c) and S2(d), the surface became smoother and the stoma disappeared after carbonization (MAC_1_800_2). Figure S3(a) shows that the nitrogen gas uptake was significant only in the lowpressure region $\left(p / p_{0}<0.2\right)$ with no further adsorption observed at higher relative pressures $\left(p / p_{0}>0.2\right)$. This Type I isotherm indicates that the resulting MAC_1_800_2 had a relatively small external surface area and micropore $(d<2 \mathrm{~nm})$ is dominating $[9,15]$. Moreover, to evaluate the pore size of the resulting carbon materials, the $t$-plot of $\mathrm{N}_{2}$ adsorption proposed by de Boer was applied, where the $y$ axis represents the amount of nitrogen adsorbed and the $x$ axis represents the $t$-value (average thickness of adsorption film) [9]. As shown in Fig. S3(b), not all the data in the $t$ plot follow a straight line passing through the starting point, thus further confirming that MAC_1_800_2 was highly microporous $[9,16]$.

Figure S3(c) shows that the nitrogen isotherm was changed by modifying the chemical dosage and activation time: the initial nitrogen uptake elevated at $p / p_{0}<0.2$; the 
knee of the isotherm became more open at $0.2<p /$ $p_{0}<0.8$; the isotherm exhibits apparent hysteresis loops when the relative pressure increased to 0.4 . This isotherm characteristic indicates the development of the mesoporosity in the resulting MAC_2.5_800_3 [15]. This result was further confirmed by $t$-plot: the elevated slop at higher $p / p_{0}$ regions means the mesopore structure was formed in MAC_2.5_800_3 (Fig. S3(d)). For the first step at $<4 \AA$, all the $\mathrm{N}_{2}$ was adsorbed as a single layer, and at $>4 \AA \mathrm{N}_{2}$ was adsorbed as a multiple layer [16]. The SEM images of the carbon may provide direct evidence: the surface become smoother (Fig. S2(e)) and some obvious pores with an average size of $20 \mathrm{~nm}$ were observed (Fig. S2(f)).

The adsorption isotherm was further changed by various activation conditions. Figure S3(e) shows that the adsorption isotherm of MAC_4_600_1 changed into Type IV with increased nitrogen uptake at higher relative $p / p_{0}$ region and an obvious desorption $\mathrm{H}_{3}$ hysteresis loop associated with capillary condensation occurred in the mesopores. Moreover, the $t$-plot shows that all the data follow a straight line passing through the starting point indicating that MAC_4_600_1 has a high mesopore ratio (Fig. S3(f)) [16]. The surfaces of MAC_4_600_1 were difficult to distinguish with MAC_2.5_800_ 3 under 2000 times magnification (Figs. S2(e) and S2(g)), but more pores and looser structure can be detected on the surface of the former carbon under closer observation (Figs. S2(f) and S2(h)).

As indicated from these observations, the effect of one factor is a change in response produced by a change in the level of another factor, thus those factors could be said to be interacting [10]. In addition, an analysis of variance (ANOVA) was employed to test for statistical significance.

\subsection{ANOVA analysis}

The results of the second-order response surface model in the form of ANOVA for mesoporosity, $V_{\text {meso }}$ and yield are shown in Tables S1, S2, and S3, respectively. From the ANOVA values for mesoporosity response in Table $\mathrm{S} 1$ the quadratic regression model demonstrates that the model is highly significant with the Fisher $F$-test $\left(F_{\text {model }}=9.470\right)$, which showed a very low probability value $\left(\left(P_{\text {model }}>F\right)=\right.$ $0.0117)$. The value of the coefficient $\left(R^{2}=0.945\right)$ indicates that only $4.5 \%$ of the total variation could not be explained by the empirical model [10]. Simultaneously, a relatively low value of the coefficient of variation $(\mathrm{CV}=16.23 \%)$ indicates good precision and reliability of the experiments [17]. Similarly, as shown in Tables S2 and S3, the results of $F_{\text {model }}=13.21,\left(P_{\text {model }}>F\right)=0.0055$, and $R^{2}=0.960$ for $Y_{2}, F_{\text {model }}=7.0,\left(P_{\text {model }}>F\right)=0.0227$, and $R^{2}=0.926$ for $Y_{3}$ show that the models were significant and fitted the responses well.

The following equations are the regression models resulting from the ANOVA analysis in terms of coded factors for responses:

$$
\begin{aligned}
\text { Mesoporosity }= & 89.97+29.04 X_{1}+3.71 X_{2}-5.85 X_{3} \\
& -21.62 X_{1}^{2}-18.07 X_{2}^{2}+0.4 X_{3}^{2} \\
& +5.98 X_{1} X_{2}+12.1 X_{1} X_{3}-4.2 X_{2} X_{3},
\end{aligned}
$$

$$
\begin{aligned}
V_{\text {meso }}= & 0.94+0.47 X_{1}+0.088 X_{2}-0.079 X_{3}-0.073 X_{1}^{2} \\
& -0.34 X_{2}^{2}+0.035 X_{3}^{2}+0.15 X_{1} X_{2}+0.067 X_{1} X_{3} \\
& -0.093 X_{2} X_{3},
\end{aligned}
$$

$$
\begin{aligned}
\text { Yeild }= & 35.17-2.06 X_{1}-3.56 X_{2}-1.13 X_{3}+0.48 X_{1}^{2} \\
& +1.23 X_{2}^{2}-0.15 X_{3}^{2}+2.63 X_{1} X_{2}+0.25 X_{1} X_{3} \\
& +X_{2} X_{3} .
\end{aligned}
$$

Figure $\mathrm{S} 4$ shows the plots of the predicted results versus the experimental data. The predicted values and measured data are distributed relatively near to the straight line $\left(R^{2}>0.92\right)$, indicating that the data can be well fit by the regression model [18].

3.3 Factors influenced on mesoporosity, mesopore volume and yields

To understand the effects of variables, the contour plots and response surface graph are drawn with one variable kept at the optimal level and the other two varying within the experimental ranges. Figure 1(a) is the $3 \mathrm{D}$ surface graph showing the effect of $\mathrm{ZnCl}_{2}$ dosage and temperature on mesoporosity. It is clear from the figure that the maximum mesoporosity occurs where the $\mathrm{ZnCl}_{2}$ dosage is within the range of 2.5 and 4 , the temperature ranges from $600^{\circ} \mathrm{C}$ to $650^{\circ} \mathrm{C}$. Previous studies have indicated that, when fabricating activated carbon from sludge, mesopores occurred only when the mass ratio of $\mathrm{ZnCl}_{2}$ to raw material was above $3.5[3,19]$. The 3D surface graph for $V_{\text {meso }}$ was similar to the graph for mesoporosity (Fig. S5(a)). These results indicate that the higher mass ratio may increase the mesoporosity and $V_{\text {meso }}$ simultaneously. At this state, the addition of $\mathrm{ZnCl}_{2}$ not only helps producing of new pores, but also improves the transformation of micropores to mesopores through pore widening $[4,19]$. As shown in Fig. S6(a) and Table 1, high total carbon yields of 35.5\%$44.0 \%$ could be obtained from run numbers $5,7,8,13$, and the corresponding $\mathrm{ZnCl}_{2}$ dosage are all at low level. But the yields sharply decrease to the range of $33 \%$ and $35 \%$, as the ratio increase from 1 to 4 (corresponding groups 12, 2,15 , and 1 ). The significant decline in total yields may be due to the high degree of impregnation which facilitated the formation of new pores and causing extra carbon burnoff [4]. On the other hand, under the lowest impregnation conditions, volatile release may be the main cause of mass 


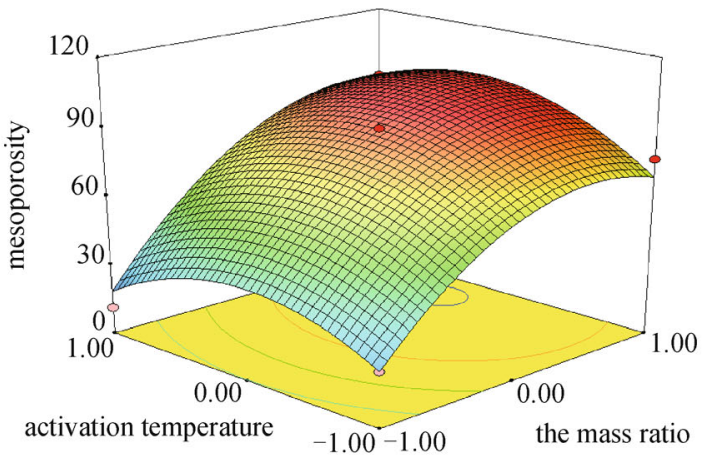

(a)

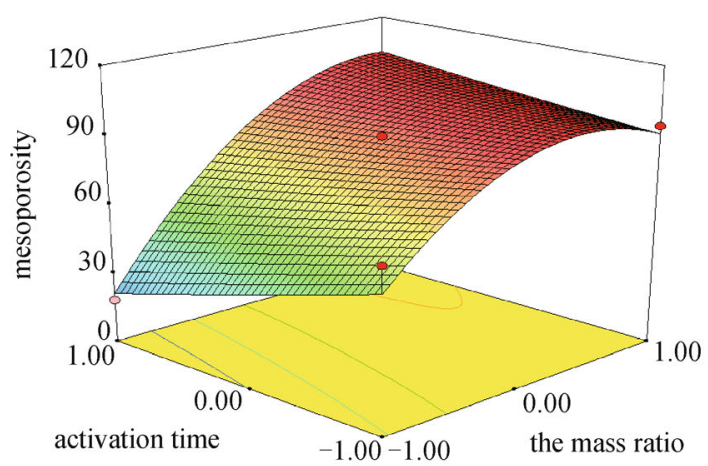

(b)

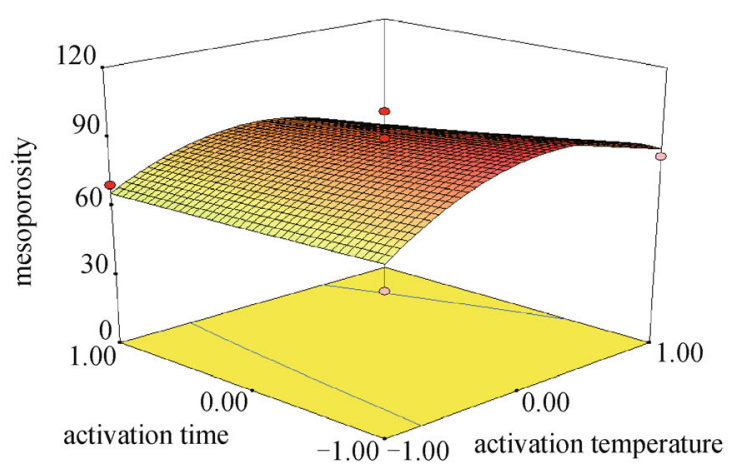

(c)

Fig. $13 \mathrm{D}$ surface graphs and contour plots of mesopore ratio showing the effect of (a) $x_{1}-x_{2}$, (b) $x_{1}-x_{3}$, (c) $x_{2}-x_{3}$

loss during activation. These results indicate that there is a trade-off between maximal mesoporosity and yield.

The interaction effects of $\mathrm{ZnCl}_{2}$ dosage and activation time on mesoporosity (Fig. 1(b)) indicate that prolonging the activation time results in improved mesoporosity at lower $\mathrm{ZnCl}_{2}$ dosage, but lowers the mesoporosity at higher $\mathrm{ZnCl}_{2}$ dosage. As shown in Table 1, the results obtained from Runs 1 and 12 (activation time 1 and $3 \mathrm{~h}$, respectively) show that prolonging the activation time lead to a decrease of $V_{\text {meso }}$ at the highest $\mathrm{ZnCl}_{2}$ dosage. Total pore volume is the sum of micropore and mesopore volumes, thus the simultaneous reduction of mesoporosity and $V_{\text {meso }}$ indicates that prolonging activation time caused breakage of mesopore at high $\mathrm{ZnCl}_{2}$ dosage (Fig. S5(b)). This was maybe resulted from over-activation, which increases surface area rather than pore formation $[6,20]$. Figure S6(b) shows that the total yield gradually reduced as activation time increased whatever the dosage of $\mathrm{ZnCl}_{2}$. Therefore, from an economic point of view, in order to obtain the maximum total yield, the activation time should be as short as possible.

Figure 1(c) denotes the interaction between pyrolysis temperature and activation time on the mesoporosity at a constant $\mathrm{ZnCl}_{2}$ dosage of 2.5. The result clearly indicates that the activation time had insignificant impact on the carbon mesoporosity. With sufficient mass ratio, $600^{\circ} \mathrm{C}$ was predicted to approximate the optimum activation temperature for production of mesopores. Figure S5(c) shows that activation time had no significant effect on $V_{\text {meso }}$ when the activation temperature was low, but slightly lowered the $V_{\text {meso }}$ of the resulting carbon when the activation temperature was high. For runs 4 and 10, as shown in Table $1, V_{\text {meso }}$ decreased from 0.811 to $0.629 \mathrm{~cm}^{3} \cdot \mathrm{g}^{-1}$, when the activation time was extended to $3 \mathrm{~h}$. These results further confirm that extra activation time sacrifices mesopores of resulting carbons and causes high burned-off. As shown in Fig. S6(c), the maximum yields could be obtained at short activation time and lower pyrolysis temperature. For example, a high yield of up to $43.5 \%$ was obtained in run 9. Low yields were obtained and were slightly affected by activation time when the activation temperature was $800^{\circ} \mathrm{C}$ and this further confirms that the JAS materials were completely carbonized.

\subsection{Multiple-response optimization}

Mesoporosity, $V_{\text {meso }}$ and yield are three individual responses and their optimization was achieved under different optimal conditions. Our objective was to obtain the maximum mesoporosity and $V_{\text {meso }}$ without sacrificing the total yield. However, it is difficult to optimize all responses under the same conditions because the interest region of different factors is different as discussed above. Thus, a compromise among the independent variables for the three responses is desirable. The overlay plot was generated by superimposing the contours for the various response surfaces. By defining the desired limits of the $V_{\text {meso }}$, mesoporosity and total yield, the shaded portion of the overlay plot defines the permissible values of the dependent variables as shown in Fig. 2. The optimum values of selected variables were obtained by solving the regression equations. The optimum values of the test variable were as follows: the chemical dosage $=2.68$, activation temperature $=526^{\circ} \mathrm{C}$, activation time $=1 \mathrm{~h}$, and the responses predicted were: $V_{\text {meso }}=0.98 \mathrm{~cm}^{3} \cdot \mathrm{g}^{-1}$, mesoporosity $=92.14 \%$ and total yield $=37.65 \%$.

Verification of the results using the set of optimized parameters was accomplished by performing the experiments incorporating the optimized variables. Two valida- 


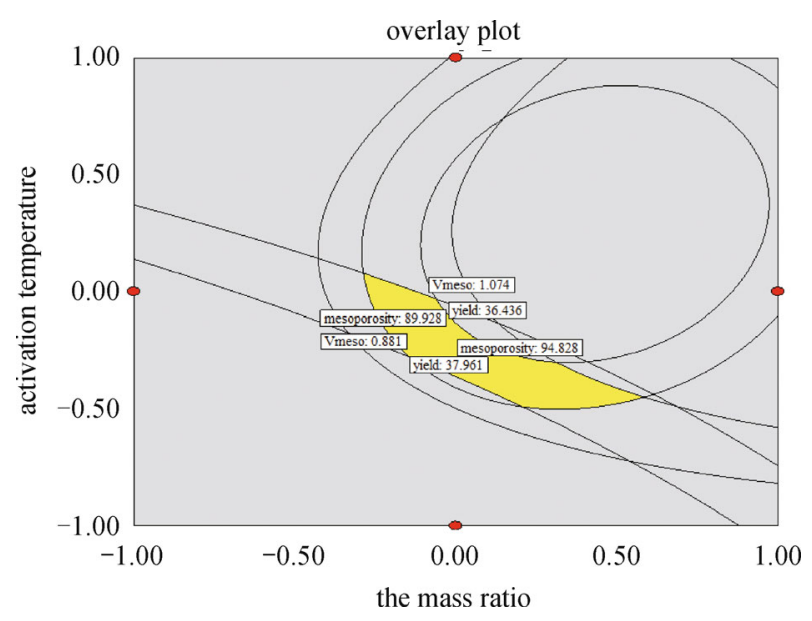

Fig. 2 Overlay plot for optimal region

tion experiments were conducted and the measured average $V_{\text {meso }}$ was $1.10 \mathrm{~cm}^{3} \cdot \mathrm{g}^{-1}$ and the average mesoporosity and the total yield were $90.16 \%$ and $36.15 \%$, respectively. These experimental results are in close agreement with the model prediction.

\subsection{Batch equilibrium adsorption}

The adsorption capacity of the MAC fabricated under the optimized condition was evaluation for $\mathrm{MB}$ adsorption. The equilibrium adsorption data were analyzed using the Langmuir, Freundlich, and Temkin isotherm models [21], and could be given as following equations:

$$
\begin{gathered}
Q_{\mathrm{e}}=\frac{Q_{\mathrm{m}} K_{\mathrm{L}} C_{\mathrm{e}}}{1+K_{\mathrm{L}} C_{\mathrm{e}}}, \\
Q_{\mathrm{e}}=K_{\mathrm{F}} C_{\mathrm{e}}^{\frac{1}{\mathrm{n}}}, \\
Q_{\mathrm{e}}=B \ln \left(A C_{\mathrm{e}}\right),
\end{gathered}
$$

where $C_{\mathrm{e}}$ is the equilibrium concentration of $\mathrm{MB}\left(\mathrm{mg} \cdot \mathrm{L}^{-1}\right)$, $Q_{\mathrm{e}}$ is the amount of $\mathrm{MB}$ absorbed per unit mass of JAS-MAC at equilibrium $\left(\mathrm{mg} \cdot \mathrm{g}^{-1}\right), Q_{\mathrm{m}}\left(\mathrm{mg} \cdot \mathrm{g}^{-1}\right)$ and $K_{\mathrm{L}}(\mathrm{L}$ $\cdot \mathrm{mg}^{-1}$ ) are the maximum adsorption capacity and Langmuir constant, respectively. $K_{\mathrm{F}}$ and $1 / n$ are isotherm constants which indicate the adsorption capacity $\left(\mathrm{mg} \cdot \mathrm{g}^{-1}\right)$ and the intensity of the adsorption, respectively. $A$ is the
Temkin constant related to equilibrium binding constant $\left(\mathrm{L} \cdot \mathrm{g}^{-1}\right)$ and $B=R T / b$, where $\mathrm{b}, R$ and $T$ are the Temkin constants the heat of adsorption $\left(\mathrm{J} \cdot \mathrm{mol}^{-1}\right)$, gas constant $\left(8.314 \mathrm{~J} \cdot \mathrm{mol}^{-1} \cdot \mathrm{K}^{-1}\right)$ and absolute temperature $(\mathrm{K})$, respectively.

The adsorption of MB on the JAS-MAC was investigated at different temperatures $(293 \mathrm{~K}, 303 \mathrm{~K}, 313 \mathrm{~K}$, and $323 \mathrm{~K})$. The experimental data were fitting by the three isotherm models as shown in Fig. 3, and the fitting values of the three models along with correlation coefficient $\left(R^{2}\right)$ are listed in Table 2. Compared to Freundlich and Temkin models, Langmuir isotherm model gives a better fit for describing the adsorption of $\mathrm{MB}$ with a relative higher $R^{2}$ (Table 2). Therefore, the uptake of MB may belong to monolayer adsorption with interactions, and the activated sites on the surface of carbons are relatively homogeneous [21]. Moreover, the essential characteristic of the Langmuir isotherm could be expressed by a dimensionless constant named equilibrium parameter $R_{\mathrm{L}}$ [22], which was defined as:

$$
R_{\mathrm{L}}=\frac{1}{1+K_{\mathrm{L}} C_{0}},
$$

where $C_{0}$ is the initial dye concentration $\left(\mathrm{mg} \cdot \mathrm{L}^{-1}\right)$. The $R_{\mathrm{L}}$ values define whether the adsorption was irreversible $\left(R_{\mathrm{L}}=\right.$ $0)$, favorable $\left(0<R_{\mathrm{L}}<1\right)$, linear $\left(R_{\mathrm{L}}=1\right)$, and unfavorable $\left(R_{\mathrm{L}}>1\right)$. The calculated $R_{\mathrm{L}}$ values (Table 2$)$ were varied from 0.01 to 0.22 at different temperature, which indicates that the MB adsorption on the JAS-MAC was favorable.

\subsection{Thermodynamic studies}

Thermodynamic parameters including Gibbs free energy change $(\Delta G)$, enthalpy $(\Delta H)$ and entropy $(\Delta S)$ are among the most important characteristics for describing an adsorption system [21,22]. The values of $\Delta H^{0}$ and $\Delta S^{0}$ were estimated according to following equations:

$$
\begin{gathered}
\ln K_{\mathrm{d}}=\frac{\Delta S^{0}}{R}+\frac{-\Delta H^{0}}{R T}, \\
\Delta G^{0}=-R T \ln K_{\mathrm{d}},
\end{gathered}
$$

\begin{tabular}{|c|c|c|c|c|c|c|c|c|c|c|}
\hline \multirow{2}{*}{$T / \mathrm{K}$} & \multicolumn{4}{|c|}{ Langmuir model } & \multicolumn{3}{|c|}{ Freundlich model } & \multicolumn{3}{|c|}{ Temkin model } \\
\hline & $Q_{\mathrm{m}} /\left(\mathrm{mg} \cdot \mathrm{g}^{-1}\right)$ & $K_{\mathrm{L}} /\left(\mathrm{L} \cdot \mathrm{mg}^{-1}\right)$ & $R_{\mathrm{L}}$ & $\overline{R^{2}}$ & $K_{\mathrm{F}} /\left(\mathrm{mg} \cdot \mathrm{g}^{-1}\right)$ & $1 / n$ & $\overline{R^{2}}$ & $A /\left(\mathrm{L} \cdot \mathrm{g}^{-1}\right)$ & B & $\overline{R^{2}}$ \\
\hline 293 & 363.6 & 1.004 & 0.010 & 0.999 & 220.4 & 0.114 & 0.963 & 884.2 & 32.3 & 0.987 \\
\hline 303 & 373.1 & 0.450 & 0.022 & 0.998 & 194.2 & 0.141 & 0.914 & 155.9 & 38.08 & 0.950 \\
\hline 313 & 374.5 & 0.536 & 0.018 & 0.999 & 200.4 & 0.136 & 0.924 & 217.8 & 37.22 & 0.964 \\
\hline 323 & 354.6 & 1.424 & 0.007 & 0.999 & 209.7 & 0.118 & 0.801 & 849.8 & 31.59 & 0.874 \\
\hline
\end{tabular}

where $R$ is the universal gas constant $\left(8.314 \mathrm{~J} \cdot \mathrm{mol}^{-1} \cdot \mathrm{K}^{-1}\right)$, $T$ is the absolute temperature $(\mathrm{K})$, and $K_{\mathrm{d}}$ is the standard thermodynamic equilibrium constant, and can be calcu-

Table 2 Langmuir, Freundlich, and Temkin isotherm constants of MB adsorption onto JAS-MAC 


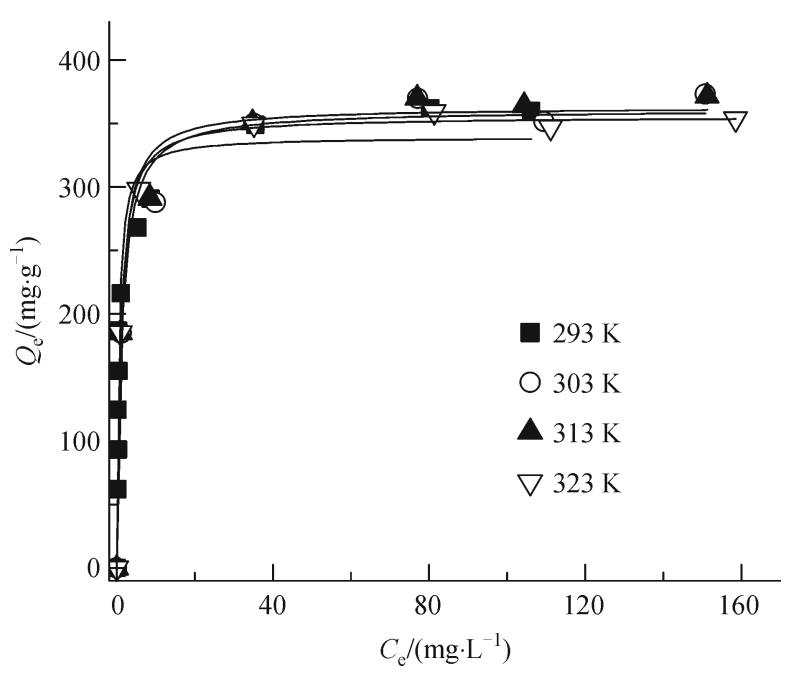

(a)

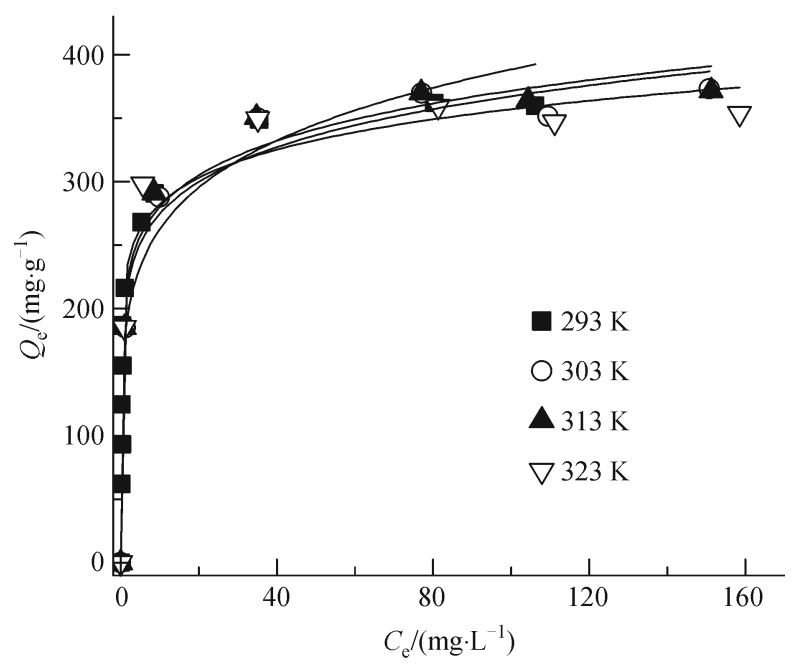

(b)

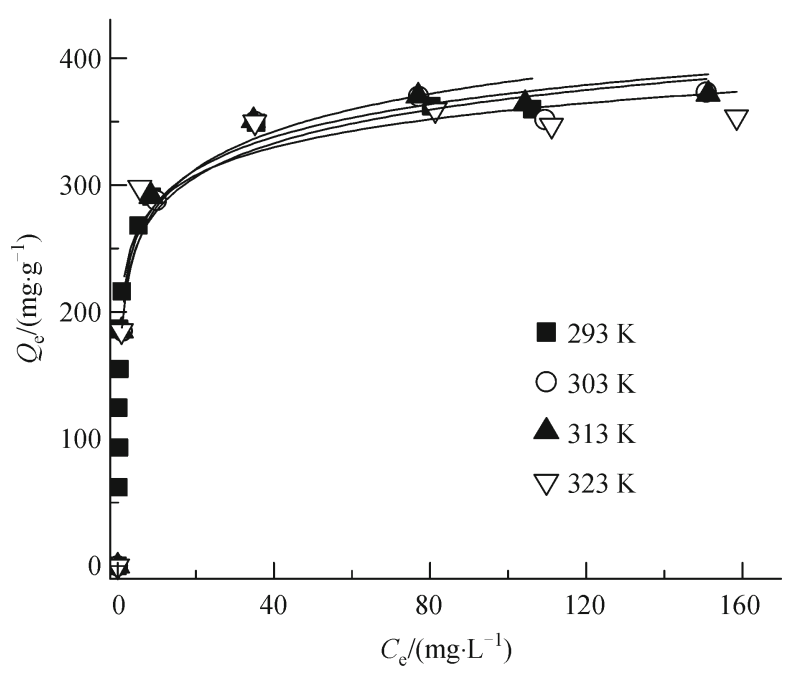

(c)

Fig. 3 Isotherm plots for the adsorption of MB onto JAS-MAC (a) Langmuir isotherm (b) Freundlich isotherm, and (c) Temkin isotherm lated as [22]:

$$
K_{\mathrm{d}}=\frac{C_{\mathrm{S}}}{C_{\mathrm{e}}}
$$

where $C_{\mathrm{S}}$ and $C_{\mathrm{e}}$ are equilibrium concentration of dye concentrations on adsorbent $\left(\mathrm{mg} \cdot \mathrm{L}^{-1}\right)$ and in the solution $\left(\mathrm{mg} \cdot \mathrm{L}^{-1}\right)$, respectively. The change in $\Delta G^{0}$ for physisorption and chemisorption are between -20 and $0 \mathrm{~kJ} \cdot \mathrm{mol}^{-1}$ and -80 to $400 \mathrm{~kJ} \cdot \mathrm{mol}^{-1}$, respectively [23]. The calculated $\Delta G^{0}$ values lies between -9.37 and $-14.10 \mathrm{~kJ} \cdot \mathrm{mol}^{-1}$ for MB adsorption, indicating that the physisorption dominates in adsorptions process and occurs spontaneously $[23,24]$. The change in enthalpy $\left(\Delta H^{0}\right)$ was $36.74 \mathrm{~kJ} \cdot \mathrm{mol}^{-1}$, suggests an endothermic nature of the adsorption process. The MB dye adsorption process by JAS-MAC could be considered as physical because $\Delta H^{0}<84 \mathrm{~kJ} \cdot \mathrm{mol}^{-1}$. The positive values of $\Delta S^{0}\left(157.38 \mathrm{~J} \cdot \mathrm{mol}^{-1}\right)$ for $\mathrm{MB}$ adsorptions suggest an increase in randomness at solid/ solution interface during the dye adsorptions [25].

\subsection{Adsorption kinetics}

Effect of contact time at different initial MB dye concentration $\left(C_{0}=100,150\right.$, and $\left.200 \mathrm{mg} \cdot \mathrm{L}^{-1}\right)$ was used to test the adsorption kinetics by JAS-MAC. Adsorption kinetics was evaluated using pseudo-first-order (PF) and pseudo-second-order (PS) kinetic models. Their nonlinear forms model can be defined as following Equations [26]:

$$
\begin{gathered}
q_{\mathrm{t}}=q_{\mathrm{e}, \mathrm{cal}}\left(1-\mathrm{e}^{-k_{1} t}\right), \\
q_{\mathrm{t}}=\frac{q_{\mathrm{e}, \mathrm{cal}}^{2} k_{2} t}{1+q_{\mathrm{e}, \mathrm{cal}} k_{2} t},
\end{gathered}
$$

where $q_{\mathrm{t}}\left(\mathrm{mg} \cdot \mathrm{g}^{-1}\right)$ is the amount of dye adsorbed at time $t$ (min), $k_{1}$ and $k_{2}$ are the PF and PS kinetic constant, respectively. The calculated $q_{\mathrm{e}, \text { cal }}$ values of PF kinetic model presented in Table 3 appeared to be much lower than $q_{\mathrm{e} \text {,exp }}$ (experimental data). The correlation coefficients $\left(R^{2}\right)$ of PF are lower than the PS model ones, indicating that MB adsorption on the JAS-MAC does not follow the PF kinetic model. Unlike PF model, the experimental data were well fitted by PS model with a higher $R^{2}$ values and the $q_{\mathrm{e}}$ values calculated by PS model are in accordance with experimental values (Table 3). This indicates that the adsorption of MB onto JAS-MAC can be well described by the PS kinetic model.

The parameter $k_{2}$ in the PS kinetic model is an overall rate constant. It does not identify the diffusion mechanism of adsorbates in the adsorption process. Therefore, intraparticle diffusion was employed to further explore the mechanism involved in the adsorption process. The diffusion process can be generally divided into three stages: film diffusion, intra-particle or pore diffusion, and sorption onto interior sites. The overall process can be described by the following Eq $[21,23]$ : 
Table 3 Kinetic parameters for the adsorption of MB onto JAS-MAC

\begin{tabular}{|c|c|c|c|c|c|c|c|c|c|c|}
\hline \multirow[b]{2}{*}{$C_{0} /\left(\mathrm{mg} \cdot \mathrm{L}^{-1}\right)$} & \multirow[b]{2}{*}{$\begin{array}{c}q_{e, \exp } \\
/\left(\mathrm{mg} \cdot \mathrm{g}^{-1}\right)\end{array}$} & \multicolumn{3}{|c|}{ Pseudo-first order } & \multicolumn{3}{|c|}{ Pseudo-second order } & \multicolumn{3}{|c|}{ intra-particle diffusion } \\
\hline & & $\begin{array}{c}q_{\mathrm{e}, \mathrm{cal}} \\
/\left(\mathrm{mg} \cdot \mathrm{g}^{-1}\right)\end{array}$ & $k_{1} / \min ^{-1}$ & $R^{2}$ & $\begin{array}{c}q_{\mathrm{e}, \mathrm{cal}} \\
/\left(\mathrm{mg} \cdot \mathrm{g}^{-1}\right)\end{array}$ & $\begin{array}{c}k_{2} \\
/\left(\mathrm{g} \cdot \mathrm{mg}^{-1} \cdot \mathrm{min}^{-1}\right)\end{array}$ & $R^{2}$ & $\begin{array}{c}\frac{k_{\mathrm{i}}}{/\left(\mathrm{mg} \cdot \mathrm{g}^{-1} \cdot \mathrm{h}^{-1 / 2}\right)}\end{array}$ & $C /\left(\mathrm{mg} \cdot \mathrm{g}^{-1}\right)$ & $R^{2}$ \\
\hline 100 & 243.6 & 228.6 & 0.034 & 0.920 & 239.1 & 1.647 & 0.961 & 18.35 & 35.58 & 0.993 \\
\hline 150 & 335.4 & 310.4 & 0.054 & 0.930 & 327.5 & 2.176 & 0.979 & 27.33 & 71.26 & 0.983 \\
\hline 200 & 374.5 & 351.1 & 0.049 & 0.937 & 369.8 & 1.678 & 0.978 & 28.65 & 80.17 & 0.976 \\
\hline
\end{tabular}

$$
q_{\mathrm{t}}=k_{\mathrm{i}} t^{0.5}+C
$$

where $k_{\mathrm{i}}\left(\mathrm{mg} \cdot \mathrm{g}^{-1} \cdot \mathrm{min}^{-1 / 2}\right)$ is the intra-particle diffusion rate constant, $C\left(\mathrm{mg} \cdot \mathrm{g}^{-1}\right)$ is the intercept. If the plot of $q_{\mathrm{t}}$ versus $t^{0.5}$ produces a straight line and pass through the origin, it means the sorption is controlled by intra-particle diffusion only. However, Fig. 4 shows a multilinear fitting of the adsorption kinetics, indicating the MB sorption onto JASMAC process is influenced by two or more steps [27]. The external surface adsorption stage was accomplished within 10 min as shown in Fig. 4, which indicated that the rate of external mass transfer is much faster than the rate of intraparticle diffusion. Moreover, the $C$ value gives information about the thickness of the boundary layer. The larger the $C$ value, the greater the contribution of the external mass transfer in the rate limiting step [25]. The large $C$ values listed in Table 3 further confirm that the intra-particle diffusion was not the rate-limiting step in the whole adsorption process [21].

\subsection{Comparison with other activated carbons}

The calculated $Q_{\mathrm{m}}$ (maximum adsorption capacity) of $\mathrm{MB}$ by JAS-MAC was $374.5 \mathrm{mg} \cdot \mathrm{g}^{-1}$, which is higher than those of particle or activated carbon $\left(303.03 \mathrm{mg} \cdot \mathrm{g}^{-1}\right)$ and granule activated carbon $\left(25.91 \mathrm{mg} \cdot \mathrm{g}^{-1}\right)$. The higher $Q_{\mathrm{m}}$ of $\mathrm{MB}$ indicates the JAS is a suitable precursor for preparation of activated carbon. Table 4 summarizes the adsorption capacity of $\mathrm{MB}$ by carbons prepared from various precursors in literature [7,19,28-32]. It can be seen

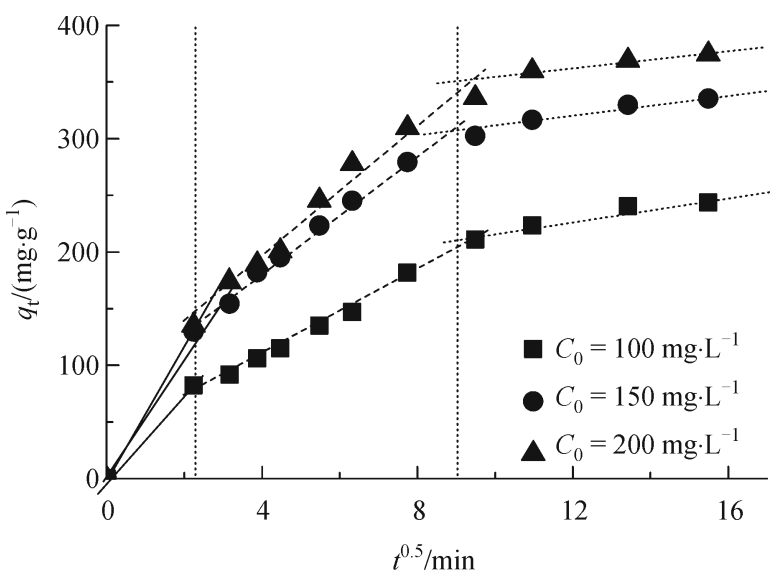

Fig. 4 Intra-particle diffusion plots for MB adsorption onto JAS-MAC that the carbon prepared in this work has a relatively high monolayer adsorption capacity compared to many other activated carbons. The high adsorption capacity of JASMAC is likely due to the higher mesoporosity and mesopore volume optimized by the statistic experimental design [20]. The plot $Q_{\mathrm{m}}$ against mesoporous volume (data collected from Table 4 , except for the data provided by Reference [19]) shows a positive correlation with $R^{2}=0.71$ $((P>F)=0.011)$. However, the plot $Q_{\mathrm{m}}$ against BET surface area shows no correlation, with a low $R^{2}$ of 0.35 $((P>F)=0.042)$ (data not shown). These results indicate that the BET surface area was not the main factor influencing on the large molecular materials adsorption by activated carbon. The carbon materials with a high proportion of mesopores provide more transport arteries, which are favorable for the large molecular adsorbates moving from the liquid to the adsorbent surface.

\section{Conclusions}

The present study shows that JAS, an agricultural byproduct waste can be carbonized and be used for fabrication of MAC, an effective low-cost adsorbent. The SEM and nitrogen gas adsorption-desorption isotherms confirm the formation of mesopores in resulting carbons. The main factors governing the three key characteristics of activated carbon (mesoporosity, mesopore volume and yield) were analyzed by RSM. The statistic results confirm that the RSM was suitable for optimizing the production of MAC from JAS. The optimum condition: the chemical dosage 2.68 , activation temperature $526^{\circ} \mathrm{C}$ and activation time $1 \mathrm{~h}$ was obtained by this method. The JAS-MAC prepared under the optimized condition showed a comparable monolayer adsorption capacity of $374.5 \mathrm{mg}$ - $\mathrm{g}^{-1}$ for MB, which was much higher than that of reported adsorbents and commercial activated carbon. The equilibrium data was well fitted by Langmuir model with a favorable adsorption. The thermodynamic analysis shows that the adsorption process of MB onto JAS-MAC was exothermic and could occur spontaneously. The effect of contact time and initial dye concentration on $\mathrm{MB}$ adsorption can be well described by pseudo second order kinetic model. The intra-particle diffusion model indicates that the film diffusion might be a rate-limiting step of the whole adsorption process. 
Table 4 Comparison adsorption capacities of various activated carbons for MB

\begin{tabular}{|c|c|c|c|c|c|c|}
\hline precursor & activating agent & $\begin{array}{c}\text { BET surface area } \\
\left(\mathrm{m}^{2} \cdot \mathrm{g}^{-1}\right)\end{array}$ & $\begin{array}{l}\text { / total Pore volume / } \\
\left(\mathrm{cm}^{3} \cdot \mathrm{g}^{-1}\right)\end{array}$ & $\begin{array}{l}\text { mesoporous pore } \\
\text { volume } /\left(\mathrm{cm}^{3} \cdot \mathrm{g}^{-1}\right)\end{array}$ & $q_{\mathrm{m}} /\left(\mathrm{mg} \cdot \mathrm{L}^{-1}\right)$ & reference \\
\hline Jerusalem artichoke stalk & $\mathrm{ZnCl}_{2}$ & 1631 & 1.22 & 1.10 & 374.5 & present study \\
\hline Piassava fibers & $\mathrm{ZnCl}_{2}$ & 1190 & 0.47 & 0.01 & 276.4 & [19] \\
\hline rice straw & $\left(\mathrm{NH}_{4}\right)_{2} \mathrm{PO}_{4}$ & 1154 & 0.67 & 0.23 & 129.5 & {$[27]$} \\
\hline durian peel & $\mathrm{CO}_{2}$ & 1015 & 0.66 & NA & 284.0 & {$[28]$} \\
\hline Pistachio nut shell & $\mathrm{KOH}$ & 700 & & 0.38 & 296.6 & [29] \\
\hline rice straw & $\mathrm{H}_{3} \mathrm{PO}_{4}$ & 790 & 0.48 & 0.18 & 107.1 & {$[30]$} \\
\hline Camellia oleifera shell & $\mathrm{H}_{3} \mathrm{PO}_{4}$ & 1608 & 1.17 & 0.95 & 330.0 & [31] \\
\hline cotton stalk & $\mathrm{H}_{3} \mathrm{PO}_{4}$ & 652 & 0.48 & 0.42 & 245.7 & [7] \\
\hline commercial powdered AC & & 1410 & 0.81 & 0.59 & 294.1 & present study \\
\hline commercial granular AC & & 581 & 0.32 & 0.10 & 35.3 & present study \\
\hline
\end{tabular}

Acknowledgements The authors acknowledge funding support from the National Natural Science Foundation of China (Grant No. 41171248) and China Postdoctoral Science Foundation funded project (2012M511330).

Supplementary material is available in the online version of this article at http://dx.doi.org/10.1007/s11783-0140631-7 and is accessible for authorized users.

\section{References}

1. Wall D A, Kiehn F A, Friesen G H. Control of Jerusalem Artichoke (Heliantbus tuberosus) in Barley (Hordeumvulgare). Weed Science, 1986, 34(5): 761-764

2. Yu L, Chen Z X, Tong X, Li K, Li W W. Anaerobic degradation of microcrystalline cellulose: kinetics and micro-scale structure evolution. Chemosphere, 2012, 86(4): 348-353

3. Liou $\mathrm{T}$ H. Development of mesoporous structure and high adsorption capacity of biomass-based activated carbon by phosphoric acid and zinc chloride activation. Chemical Engineering Journal, 2010, 158(2): 129-142

4. Hu Z H, Srinivasan M P, Ni Y M. Preparation of mesoporous highsurface area activated carbon. Advanced Materials, 2000, 12(1): 62 65

5. Gupta V K, Gupta B, Rastogi A, Agarwal S, Nayak A. A comparative investigation on adsorption performances of mesoporous activated carbon prepared from waste rubber tire and activated carbon for a hazardous azo dye-Acid Blue 113. Journal of Hazardous Materials, 2011, 186(1): 891-901

6. Zhu Z L, Li A, Yan L, Liu F Q, Zhang Q X. Preparation and characterization of highly mesoporous spherical activated carbons from divinylbenzene-derived polymer by $\mathrm{ZnCl}_{2}$ activation. Journal of Colloid and Interface Science, 2007, 316(2): 628-634

7. Deng H, Zhang G L, Xu X L, Tao G H, Dai J L. Optimization of preparation of activated carbon from cotton stalk by microwave assisted phosphoric acid-chemical activation. Journal of Hazardous Materials, 2010, 182(1-3): 217-224

8. Dubey S P, Dwivedi A D, Sillanpää M, Gopal K. Artemisia vulgaris-derived mesoporous honeycomb-shaped activated carbon for ibuprofen adsorption. Chemical Engineering Journal, 2010, 165 (2): 537-544

9. Khalili N R, Campbell M, Sandi G, Golas J. Production of microand mesoporous activated carbon from paper mill sludge. I. Effect of zinc chloride activation. Carbon, 2000, 38(14): 1905-1915

10. Ahmad A L, Ismail S, Bhatia S. Optimization of coagulationflocculation process for palm oil mill effluent using response surface methodology. Environmental Science \& Technology, 2005, 39(8): 2828-2834

11. Baçaoui A, Yaacoubi A, Dahbi A, Bennouna C, Phan Tan Luu R, Maldonado-Hodar F J, Rivera-Utrilla J, Moreno-Castilla C. Optimization of conditions for the preparation of activated carbons from olive-waste cakes. Carbon, 2001, 39(3): 425-432

12. Theydan S K, Ahmed M J. Optimization of preparation conditions for activated carbons from date stones using response surface methodlogy. Powder Technology, 2012, 224: 101-108

13. Quintana J B, Rodil R, López-Mahía P, Muniategui-Lorenzo S, Prada-Rodríguez D. Investigating the chlorination of acidic pharmaceuticals and by-product formation aided by an experimental design methodology. Water Research, 2010, 44(1): 243-255

14. d' Almeida A L F S, Barreto D W, Calado V, d'Almeida J R M. Thermal analysis of less common lignocellulose fibers. Journal of Thermal Analysis and Calorimetry, 2008, 91(2): 405-408

15. Warhurst A M, Fowler G D, McConnachie G L, Pollard S J T. Pore structure and adsorption characteristics of steam pyrolysis carbons from Moringa oleifera. Carbon, 1997, 35(8): 1039-1045

16. Tamai H, Kakii T, Hirota Y, Kumamoto T, Yasuda H. Synthesis of extremely large mesoporous activated carbon and its unique adsorption for giant molecules. Chemistry of Materials, 1996, 8 (2): 454-462

17. Kuehl R O. Design of Experiments: Statistical Principles of Research Design and Analysis. 2nd ed. Pacific Grove, CA: Duxbury Press, 2000, 2-225

18. Ghasempur S, Torabi S F, Ranaei-Siadat S O, Jalali-Heravi M, Ghaemi N, Khajeh K. Optimization of peroxidase-catalyzed oxidative coupling process for phenol removal from wastewater using response surface methodology. Environmental Science \& 
Technology, 2007, 41(20): 7073-7079

19. Avelar F F, Bianchi M L, Gonçalves M, G Mota E. The use of piassava fibers (Attalea funifera) in the preparation of activated carbon. Bioresource Technology, 2010, 101(12): 4639-4645

20. Okada K, Yamamoto N, Kameshima Y, Yasumori A. Porous properties of activated carbons from waste newspaper prepared by chemical and physical activation. Journal of Colloid and Interface Science, 2003, 262(1): 179-193

21. Ghaedi M, Sadeghian B, Pebdani A A, Sahraei R, Daneshfar A, Duran C. Kinetics, thermodynamics and equilibrium evaluation of direct yellow 12 removal by adsorption onto silver nanoparticles loaded activated carbon. Chemical Engineering Journal, 2012, 187: 133-141

22. Duranoğlu D, Trochimczuk A W, Beker U. Kinetics and thermodynamics of hexavalent chromium adsorption onto activated carbon derived from acrylonitrile-divinylbenzene copolymer. Chemical Engineering Journal, 2012, 187: 193-202

23. Mahmoodi N M, Hayati B, Arami M, Lan C. Adsorption of textile dyes on pine cone from colored wastewater: kinetic, equilibrium and thermodynamic studies. Desalination, 2011, 268(1-3): 117-125

24. Ahmad R, Kumar R. Adsorptive removal of Congo Red dye from aqueous solution using bael shell carbon. Applied Surface Science, 2010, 257(5): 1628-1633

25. Toor M, Jin B. Adsorption characteristics, isotherm, kinetics and diffusion of modified natural bentonite for removing diazo dye.
Chemical Engineering Journal, 2012, 187: 79-88

26. Ocampo-Perez R, Leyva-Ramos R, Mendoza-Barron J, GuerreroCoronado R M. Adsorption rate of phenol from aqueous solution onto organobentonite: surface diffusion and kinetic models. Journal of Colloid and Interface Science, 2011, 364(1): 195-204

27. Vadivelan V, Kumar K V. Equilibrium, kinetics, mechanism, and process design for the sorption of methylene blue onto rice husk. Journal of Colloid and Interface Science, 2005, 286(1): 90-100

28. Gao P, Liu Z H, Xue G, Han B, Zhou M H. Preparation and characterization of activated carbon produced from rice straw by $\left(\mathrm{NH}_{4}\right)_{2} \mathrm{HPO}_{4}$ activation. Bioresource Technology, 2011, 102(3): 3645-3648

29. Nuithitikul K, Srikhun S, Hirunpraditkoon S. Influences of pyrolysis condition and acid treatment on properties of durian peel-based activated carbon. Bioresource Technology, 2010, 101(1): 426-429

30. Foo K Y, Hameed B H. Preparation and characterization of activated carbon from pistachio nut shells via microwave-induced chemical activation. Biomass and Bioenergy, 2011, 35(7): 3257-3261

31. Basta A H, Fierro V, Saied H, Celzard A. Effect of deashing rice straws on their derived activated carbons produced by phosphoric acid activation. Biomass and Bioenergy, 2011, 35(5): 1954-1959

32. Kang S, Jianchun J, Dan Dan C. Preparation of activated carbon with highly developed mesoporous structure from Camellia oleifera shell through water vapor gasification and phosphoric acid modification. Biomass and Bioenergy, 2011, 35(8): 3643-3647 